\title{
Variations of Moisture Content in Manufacturing CLT-Concrete Composite Slab Using Wet Construction Method
}

\author{
Yo-Jin Song, Seong-Yeob Baek, In-Hwan Lee, and Soon-Il Hong*
}

\begin{abstract}
Construction of eco-friendly high-rise buildings using cross-laminated timber (CLT)-concrete composite (CCC) slabs is increasing. CLT and concrete, which are major component materials of the CCC slab, are significantly affected by moisture. In particular, the moisture content of concrete in the production process affects the quality of both materials. In this study, the effects of the wet construction method on CLT and concrete component materials are examined by monitoring the behavior of the CCC slab during curing time ( $28 \mathrm{~d}$ ) and by evaluating the quality of the concrete and CLT after curing. When manufacturing the CCC using the wet construction method, moisture penetration from the concrete into the CLT during the curing time is suppressed by the shear bonding between the concrete and the CLT when an adhesive is used. This minimizes the effect of the moisture on both component materials, consequently yielding uniform compressive strength to the concrete after curing and preventing the deterioration of the CLT's delamination performance. Therefore, the shear bonding method using an adhesive is expected to minimize the quality deterioration observed in concrete and CLT after curing.
\end{abstract}

Keywords: CLT-concrete composite; TCC slab; TCC curing; Cross-laminated timber; CLT delamination; TCC deflection

Contact information: Department of Forest Biomaterials Engineering, Kangwon National University, Chun-Cheon 200-701, South Korea; *Corresponding author: hongsi@kangwon.ac.kr

\section{INTRODUCTION}

The global urbanization percentage is currently $55 \%$ and is forecasted to reach $68 \%$ by 2050 (United Nations 2018). The construction of new concrete buildings and extension or renovation of old ones is continually required for urban regeneration. Using engineered wood structures instead of concrete, the main material of the construction industry, can contribute to environmentally friendly urban designs (Song et al. 2019). The use of engineered wood structures will contribute to the construction of environment-friendly cities by reducing the inevitable carbon emissions for urban development and growth (Darby et al. 2013; Lehmann 2013; Dodoo et al. 2014; Liu et al. 2016). Cross-laminated timber (CLT) is an engineered wood structure panel in which the visually or mechanically graded laminae have been cross-laminated in three or more layers $(3,5,7$, or more layers in general). Buildings using CLT panels have the advantage of a shortened construction period and construction cost savings because their self-weight can be reduced by approximately $1 / 5$, compared to that of concrete buildings with the same number of floors (Mahdavifar et al. 2016; Liao et al. 2017; Jiang and Crocetti 2019). When CLT is used as a floor slab it must be designed with a sufficient thickness to meet requirements for the structural aspects, fire resistance, and interlayer noise caused by deflection and vibration (Park and Lee 2019). However, increasing the thickness of the floor slab can cause other 
issues, such as reduced equipment space or low story height. The use of timber-concrete composite (TCC), a combination of timber and concrete, can address these problems. In TCC slabs, the timber part can endure the tensile force, but the concrete portion resists the compressive force and endures the bending moment (Teguedy et al. 2019). This structure is a promising and feasible solution that can compete with steel and reinforced concrete structures in some applications. In particular, the TCC floor system has a higher fire performance than the only timber floor system, and the studies on such improvement in fire performance and fire conditions play a part in increasing mass timber buildings (Frangi et al. 2010; Ogrin and Hozjan 2020). Therefore, the construction of eco-friendly high-rise buildings using CLT-concrete composite (CCC) slabs is increasing worldwide (Harte 2017; Mai et al. 2018; Timmers and Jacobs 2018).

There are two ways of producing CCC: by connecting individually cured concrete with a CLT or by directly pouring concrete into a CLT. The latter, which is the wet construction method, offers various options for full composite design of CLT and concrete, which must be considered first when manufacturing CCC slabs. Furthermore, it improves the ease of bonding a CLT floor with pillars, walls, or beams in the field. Therefore, with regard to the $\mathrm{CCC}$ manufacture method, between pouring concrete over a CLT floor structure in the field (wet construction method) or pre-fabricating CCC in a factory, the former is predominant (Kanócz and Bajzecerová 2015; Bajzecerová 2017; Thilén 2017; Jiang and Crocetti 2019; Mudie et al. 2019; Teguedy et al. 2019; Fu et al. 2020). When CCC is manufactured through the wet construction method, the CLT plays the subgrade role of concrete. Because CLT is a porous material, it will cause the loss of the concrete mixing water. Simultaneously, if the CLT absorbs the concrete mixing water, the moisture content of the wood will increase. The moisture transfer between concrete and CLT will change the curing conditions of concrete, which is the main material of CCC. Curing will increase the differences in moisture and temperature between the concrete surface and subgrade, and this will cause concrete curl during curing (Heath and Roesler 2000; Burnham and Koubaa 2001; Lim et al. 2009; Jeong et al. 2012; Shen et al. 2019). Above all, the moisture transfer between concrete and CLT can affect the water-cement (W/C) ratio of concrete. In the concrete mix design, the $\mathrm{W} / \mathrm{C}$ ratio is correlated with workability, the concrete slump value, the material separation (bleeding) phenomenon during construction, and the generation of an uncured layer during curing. These parameters can ultimately affect the structural stability of the material, such as decreasing the concrete strength, creating concrete cracks, causing the creep phenomenon to occur, and increasing the lateral pressure (Tumidajski and Gong 2006; Adesanya and Raheem 2009; Meddah et al. 2010; Alawode and Idowu 2011). The water transfer between concrete and CLT will affect the quality of CLT, which is another major component material of CCC. Because timbers generally have a larger density of latewood than earlywood, the latewood undergoes greater contraction, which causes cupping of the cross-section in the direction opposite the annual rings. Cupping occurs in the laminae of each layer when the CLTs exposed to a wet environment are dried. This dry stress by contraction causes lamination of the CLTs by inducing shear force inside the bondline with the adjacent laminae (Song and Hong 2016; Song et al. 2019; Lim et al. 2020). In particular, the interlayer laminae contract in opposite directions of each other because the CLTs are laminated orthogonally to the fiber direction of the interlayer laminae. Due to this characteristic, CLTs have a lower bonding performance compared to the laminated timber that has been laminated parallel to the fiber direction between the layers (Gong et al. 2016; Song and Hong 2016; Knorz et al. 2017). The CCC production through the wet construction method raises the possibility that 
some of the concrete mixing water will penetrate the CLT immediately after concrete pouring. This possibility must be examined because it may cause CLT delamination over a long time, during curing, and even after it.

In this study, the effects of the concrete moisture on the major component materials in CCC slab production were examined using the wet construction method. The shear connection method between CLT and concrete and the curing behavior according to the concrete thickness was monitored. After the end of curing (28 d), the effects of the concrete moisture on the quality of the component materials were examined through the compressive strength of concrete and a delamination test of the CLT.

\section{EXPERIMENTAL}

\section{Materials}

Cross-laminated timber and concrete

The CLT was produced in five layers using larch (Larix kaempferi Carr.) laminae (National Forestry Cooperative Federation, Yeoju-si, South Korea). The longitudinal layer of larch CLT was composed of laminae with an average modulus of elasticity of $15 \mathrm{GPa}$ and the transverse layer was randomly composed of laminae with a modulus of elasticity of 13 GPa or lower. The laminae were laminated by applying phenol-resorcinol formaldehyde (PRF) to the surfaces of the laminae (Kangnam Chemical, Seoul, South Korea), and side bonding was not performed. A $400 \mathrm{~g} / \mathrm{m}^{2}$ application amount (one-side application) and 1.0 MPa pressure was applied (Song and Hong 2016). The average air-dry moisture content of the CLT was $9.1 \%$, the average air-dry density was $580 \mathrm{~kg} / \mathrm{m}^{3}$, and the size was $150(\mathrm{t}) \times$ $170(w) \times 2100(1) \mathrm{mm}^{3}$.

The $\mathrm{W} / \mathrm{C}$ ratio of concrete in the mixing design was 0.43 , the maximum aggregate size was $25 \mathrm{~mm}$, and the design strength was $24 \mathrm{MPa}$. The compressive strength test for the specimen was based on the ASTM C39 (2012) standard. The average compressive strength after curing was $34.9 \mathrm{MPa}$ for $7 \mathrm{~d}$ and $40.7 \mathrm{MPa}$ after curing for $28 \mathrm{~d}$.

\section{CLT-concrete composite}

Four types of CCC were fabricated (Fig. 1). For Series-A, Series-C, and Series-D, it was assumed that the CLT and concrete would be mechanically bonded to each other in practice by shear connectors. The actual specimens were fabricated without bonding so that the compressive strength of the concrete could be collected and a delamination test on the CLTs could be conducted after curing. The presence or absence of shear connectors affects the bending strength, but it was considered to have had no remarkable effect on moisture transfer in this study.

The Series-A specimen was fabricated by directly pouring 50 -mm-thick concrete over the CLT with no bonding agent. The Series-B specimen was fabricated by pouring 50-mm-thick concrete after applying an epoxy adhesive to the plane of the CLT (bondline thickness: $1 \mathrm{~mm}$ ). The Series-C specimen was fabricated by reinforcing the CLT through the application of 1.2-mm-thick carbon-fiber-reinforced plastic (CFRP) to the entire surface of the tensile zone. A polyurethane adhesive was used for the bonding of the CLT and CFRP (Song et al. 2019). Series-D was a specimen whose concrete thickness was increased to three times that of Series-A and for which shear connection between concrete and CLT was not performed, as with Series-A and Series-C. Concrete was poured onto the CLT of every specimen after the mold was made, and the moisture of concrete was 
prevented from leaking into the gap between the CLT and the formwork using a glue gun. A total of eight specimens were fabricated, with two specimens for each series.

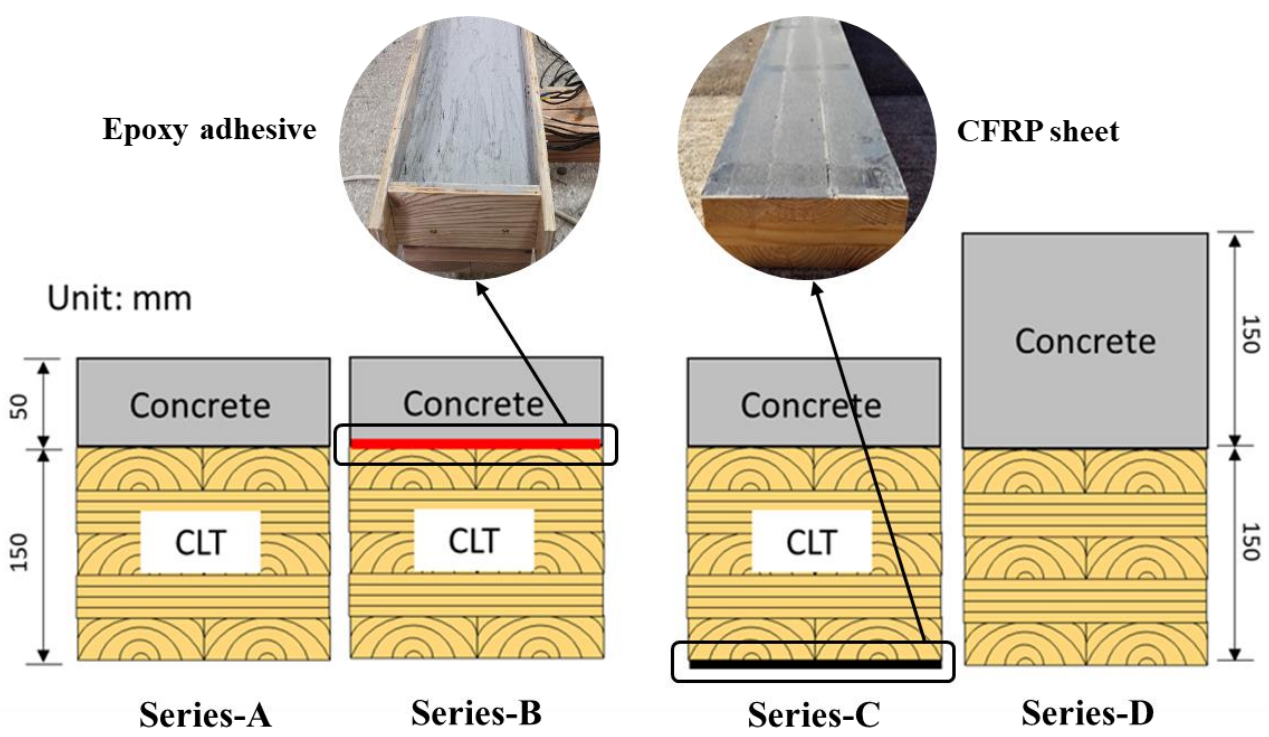

Fig. 1. Fabrication method of CCC slabs for each series; carbon-fiber-reinforced plastic (CFRP)

\section{Methods}

Moisture content and deflection behavior monitoring of CLT-concrete composite during concrete curing

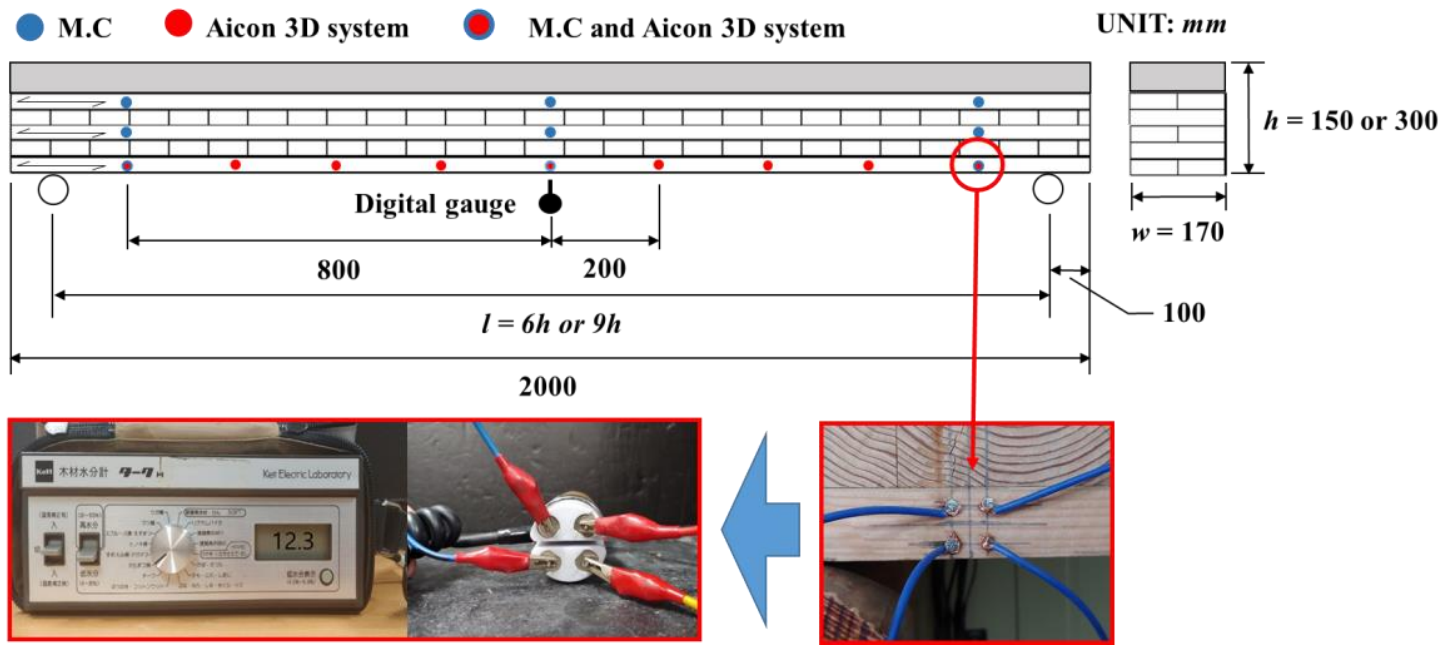

Fig. 2. Monitoring test setup and CLT moisture content measuring method during the curing time of CCC slab

The CCC slab was cured in a room ventilated with outdoor air. During the curing time, the moisture content was measured in the laminae in the fiber direction at the center of the CLT and at $800 \mathrm{~mm}$ to the left and right. The moisture content was measured by inserting one side of the sheathed wire into a lamina and making the other side contact an electrical resistance moisture meter (K-100; KETT Electric Laboratory, Tokyo, Japan) (Fig. 2). The measurement of the moisture content for the electrical resistivity can generate 
an error in actual timber. Therefore, separate small timbers of larch were exposed to the same temperature and humidity conditions for $40 \mathrm{~d}$, and then the correlation between the actual moisture content of timber and the electrical resistivity was checked through the oven dry method as per KS F 2199 (2016), which is closest to the actual moisture content of timber (Fig. 3). As a result, the calibration function formula was derived, as shown in Fig. 4, and the moisture content measured for the electrical resistivity using the calibration function formula was calculated as the actual moisture content.

The interval between the points was set as $9 \mathrm{~h}$ for Series-A, Series-B, and Series$\mathrm{C}$, and $6 \mathrm{~h}$ for Series-D. The total deflection was measured using a digimatic indicator (IDS1012; Mitutoyo Corp, Kawasaki, Japan) at the bottom center of the CCC slab. The moisture content and deflection were measured once a day for a total of $29 \mathrm{~d}$, from the day before concrete pouring until the $28^{\text {th }}$ day after pouring. For Series-D1, image analysis for the behavior was performed three times, on the $10^{\text {th }}, 20^{\text {th }}$, and $29^{\text {th }}$ day after concrete pouring, using AICON 3D studio (AICON 3D Systems, DPA Professional, Braunschweig, Germany), while measuring the deflections with a digital displacement meter.

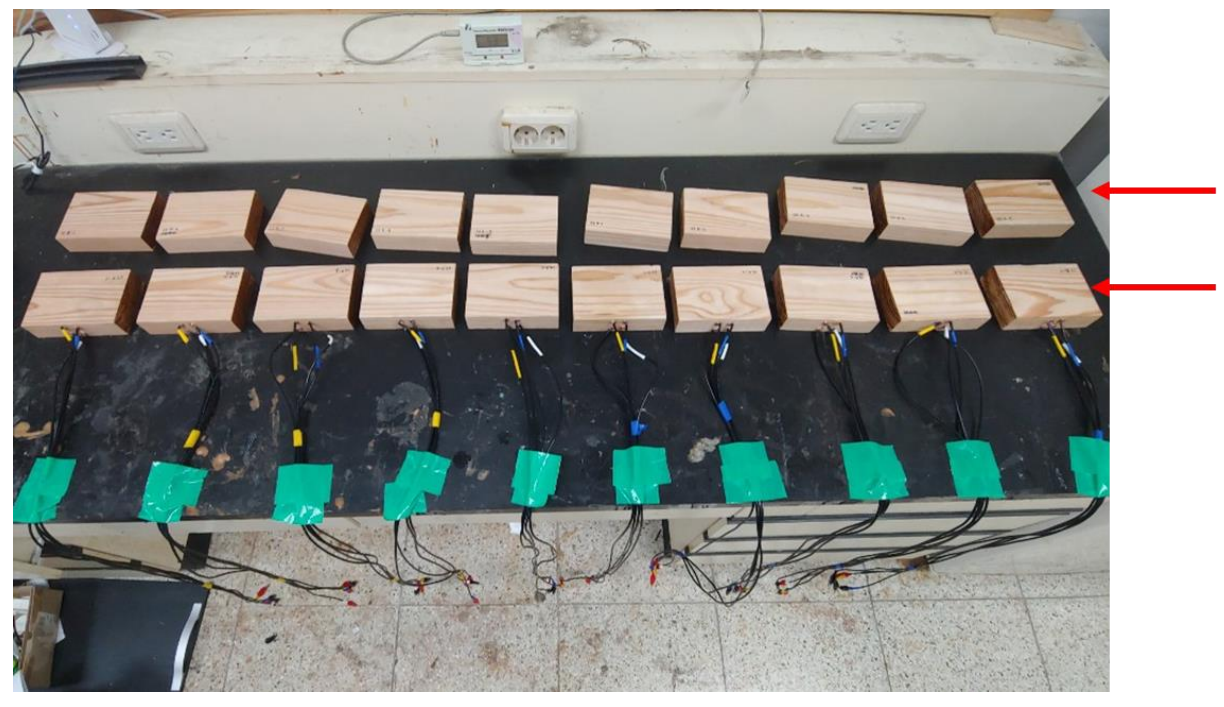

Oven dry after 40 days

Electrical resistivity moisture meter

Fig. 3. Preliminary test for the calculation of the calibration moisture content of the electrical resistivity-moisture content measurement method

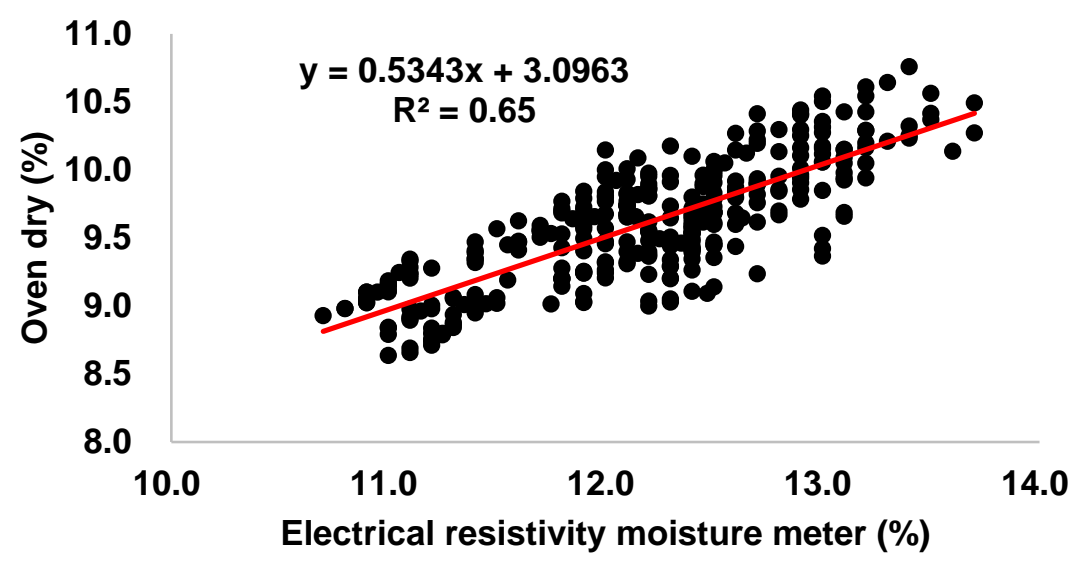

Fig. 4. Correlation between oven dry and electrical resistivity moisture meter 


\section{Quality Performance Evaluation of CCC after Curing for 28 Days}

Compressive strength test for the concrete of CCC

When concrete is poured over the CLT, the water contained by concrete is absorbed by the CLT, and the moisture weight can be lower than that of the mixing design, thus affecting the mix strength. Therefore, the compressive strength was tested in this study by sampling the concrete after the curing of the CLT-concrete composite.

The compressive strength test for concrete was performed on Series-A, Series-B, and Series-D. Series-C was excluded because its bonding method was the same as that of Series-A. The compressive-strength specimen was fabricated as a cube with a 50-mm side length considering the concrete thickness of the CLT-concrete composite. The test was performed with a universal testing machine (DYHU-200TX-A/D; Daeyeong Precision, Gunpo-si, South Korea) with a maximum capacity of 200 tons, and the test speed was 2 $\mathrm{mm} / \mathrm{min}$.

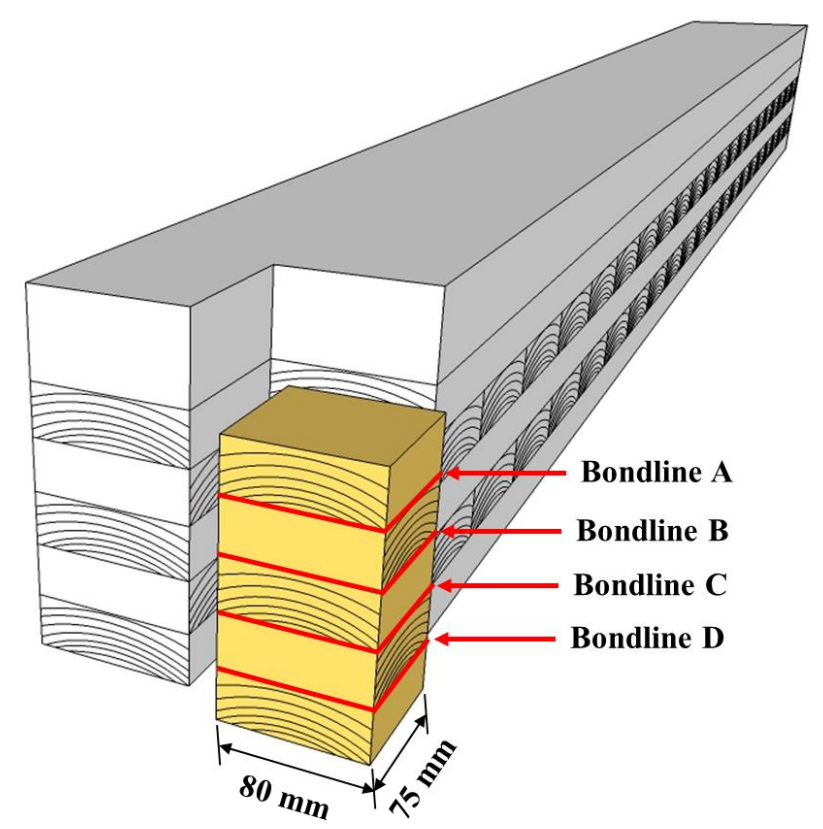

Fig. 5. Description of the delamination specimen collection and bondline of the CLT

\section{Delamination test for the CLT of CCC}

The delamination performance of the CLT after curing was evaluated to determine if the concrete moisture affected the quality of the CLT during concrete curing. Evaluation of the delamination performance was performed for Series-A, Series-B, and Series-D. Series-C was excluded because its bonding method was the same as that of Series-A. Ten soaking and boiling specimens were taken each from series-A, series-B, and series-D. The specimens were $150 \mathrm{~mm}$ in height, $80 \mathrm{~mm}$ in width, and $75 \mathrm{~mm}$ in length. For the soaking delamination test, the specimen was soaked in water at room temperature $\left(10\right.$ to $\left.25^{\circ} \mathrm{C}\right)$ for $1 \mathrm{~h}$, and then dried in a constant-temperature dryer $\left(70 \pm 3{ }^{\circ} \mathrm{C}\right)$ until the dried weight was 90 to $110 \%$ of the weight before drying. For the boiling delamination test, the specimen was boiled in water for $4 \mathrm{~h}$ and then soaked in water at room temperature $\left(10\right.$ to $\left.25^{\circ} \mathrm{C}\right)$ for $1 \mathrm{~h}$ and dried in a constant-temperature dryer $\left(70 \pm 3{ }^{\circ} \mathrm{C}\right)$ until the dried weight was 90 to $110 \%$ of the weight before drying. The delamination by defects such as knots and 
woodcutting was excluded when the specimen's delamination length was measured as per KS F 2160 (2013) and KS F 3021 (2013) standards.

\section{RESULTS AND DISCUSSION}

\section{Behavior of the CLT-concrete Composite During Concrete Curing}

Variations of the moisture content of the CLT

Figure 6 shows the results of the variations in moisture content and deflection of the CCC slab. The moisture content graph of each layer depicts the average of the moisture contents measured at three points of the longitudinal laminae.
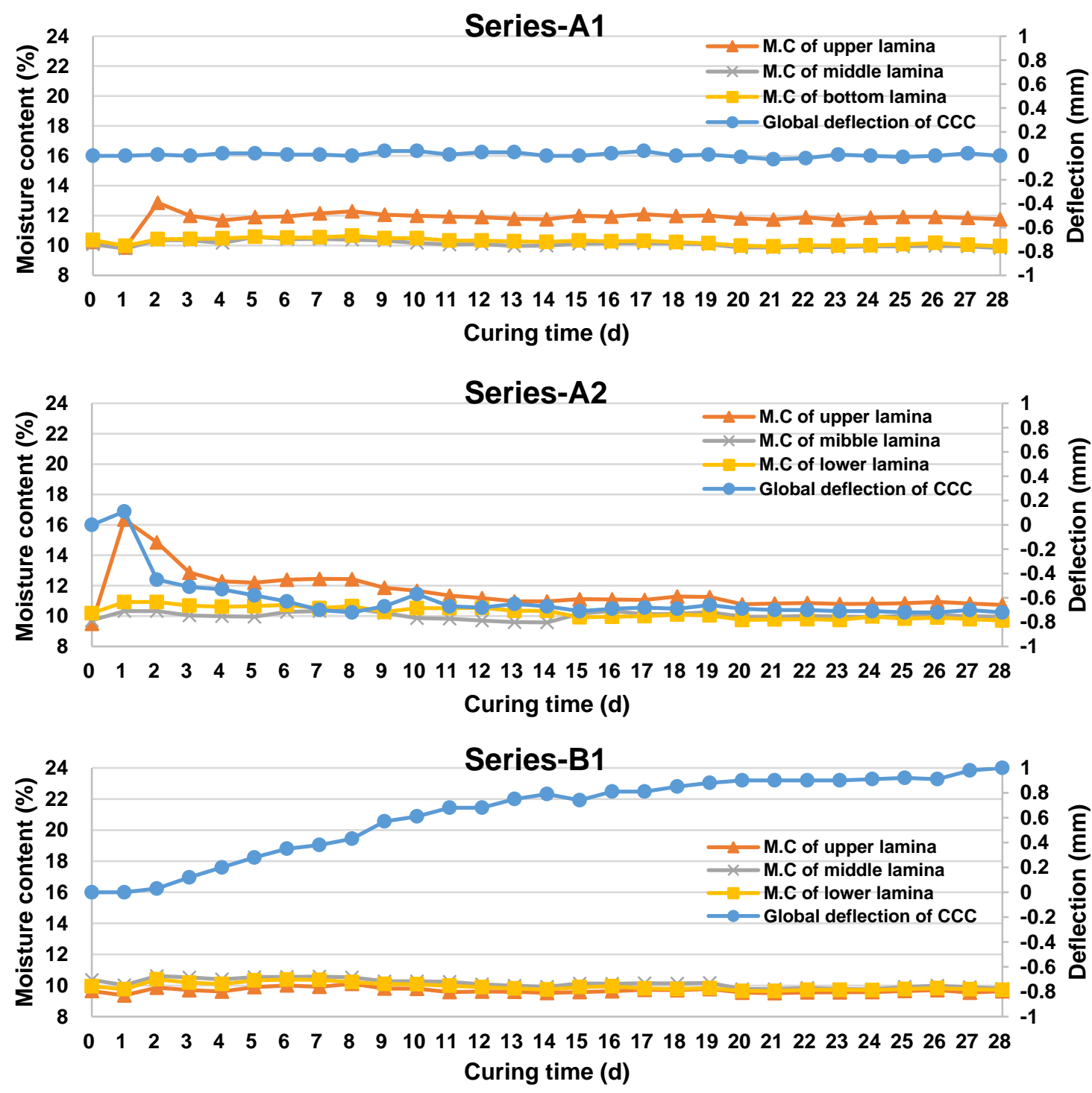

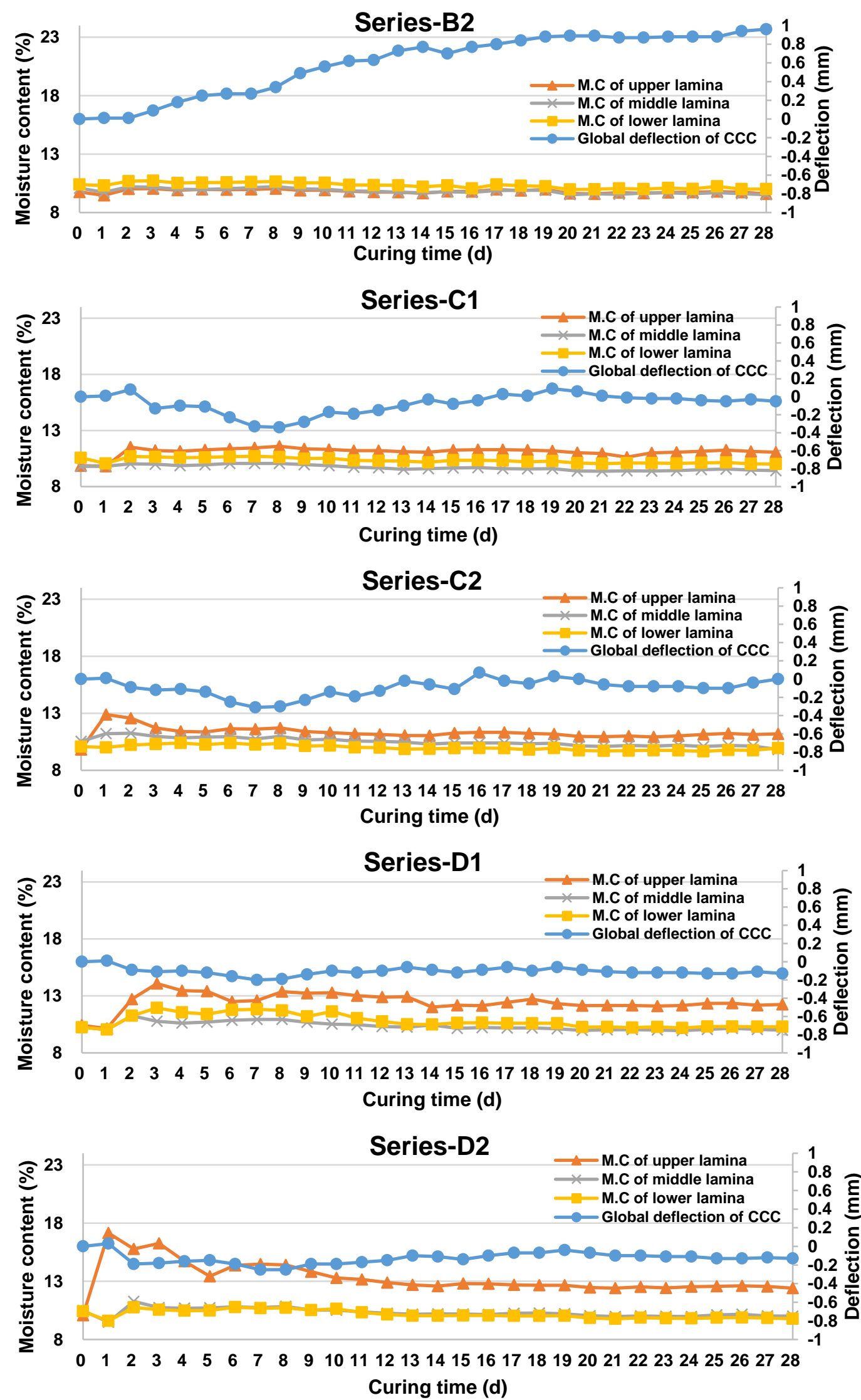

Fig. 6. Variations in moisture content and deflection of the CCC slabs during the curing time 
The largest variation in moisture content of the upper lamina of the CLT in contact with the concrete of Series-A, Series-C, and Series-D was observed between 1 and $3 \mathrm{~d}$ after concrete pouring, and the penetration of CLT by concrete moisture was verified. During the same period, the maximum moisture content $\left(\mathrm{MC}_{\max }\right)$-to-initial moisture content $\left(\mathrm{MC}_{0}\right)$ ratios of the upper laminae of Series-A, Series-C, and Series-D were 1.49, 1.25, and 1.53, respectively. Here, the differences in maximum moisture content in the same series appear to be due to the water transfer inside the concrete, or the differences in the properties of the CLT's upper lamina according to the degree of compaction. Then, the moisture content of the upper lamina showed a decreasing tendency with the progress of the curing time, but the $\mathrm{MC}_{28}$ (moisture content after curing for $28 \mathrm{~d}$ )-to- $\mathrm{MC}_{0}$ ratios of the upper laminae of Series-A, Series-C, and Series-D were 1.14, 1.13, and 1.20, respectively. Immediately after concrete pouring, part of the concrete moisture was expected to penetrate the CLT's upper lamina. The moisture in the concrete generally decreased approximately $25 \%$ due to the hydration reaction that occurs between 4 and $10 \mathrm{~h}$ after pouring, but a large amount of moisture remained inside the concrete during the curing time. The moisture in the concrete kept the contact surface between the CLT and the concrete in a wet condition, which meant that the CLT was affected by the concrete water even after CLT's curing time of $28 \mathrm{~d}$. In contrast to the upper lamina, the middle and lower laminae showed little or no moisture content variation.

Meanwhile, in the case of Series-B, which was bonded using an epoxy adhesive, the $\mathrm{MC}_{\max }$-to- $\mathrm{MC}_{0}$ ratio of the upper lamina slightly increased to 1.04 . The $\mathrm{MC}_{28}$-to- $\mathrm{MC}_{0}$ ratio decreased to 0.99 . This result indicated that the epoxy bondline suppressed the moisture penetration from concrete to timber.

On the first day of pouring, it was observed that the moisture content in every lamina of most of the CCC slabs slightly decreased. It is considered that the CLT moisture was dried by the sharp temperature rise of concrete due to the hydration reaction that occurred immediately after pouring, and that the moisture content increased again.

\section{Variation of deflection of the CLT}

Series-A showed different deflection tendencies of A1 and A2, depending on the high or low increase in the moisture content of the CLT's upper lamina. For A1, the increase in the moisture content of the upper lamina in the early stage of curing was low. Consequently, swelling due to moisture did not occur in the CLT's upper lamina. Moreover, CLT deformation did not occur because the CLT's upper lamina did not quickly dry $2 \mathrm{~d}$ after the measurement of the maximum moisture content. The self-weight of concrete did not have a significant effect on the CLT's deflection, but unlike Series-A1, the upper lamina of Series-A2's CLT absorbed a large amount of moisture, thus greatly increasing the moisture content on the $1^{\text {st }}$ day of curing. At this time, swelling of the CLT's upper lamina occurred, and the upward deflection increased significantly $(-0.45 \mathrm{~mm})$ on the $3^{\text {rd }}$ day of curing. After that, even when the CLT's upper lamina was dried, the deflection did not recover and was $-0.72 \mathrm{~mm}$ on the $28^{\text {th }}$ day of curing. The CLT of SeriesB was not affected by moisture, but the deflection of Series-B was affected by the deformation due to the curing behavior of concrete. As soon as the bottom side of the concrete whose moisture was not lost by the bondline had a humid condition, it became warm due to heating by the hydration heat of the concrete itself and the curing reaction of the epoxy adhesive. These curing conditions made the concrete surface relatively cool and dry. As a result, the surface contracted quickly, and this caused the upward curling of the concrete. The upward curling of this composite showed a tendency of downward deflection 
due to the span. In Series-C, as with Series-A2, swelling occurred in the upper lamina of the CLT due to moisture absorption, and the deflections of Series-C1 and Series-C2 were measured at $-0.35 \mathrm{~mm}$ and $-0.32 \mathrm{~mm}$, respectively, on the $8^{\text {th }}$ day of curing, the upward deflection of Series-C no longer increased due to the CFRP sheet reinforcement in the CLT bottom side. The CFRP is a hygroscopic material. Therefore, the CFRP did not immediately suppress the deflection of CLT in the beginning of curing, but the deflection was gradually recovered from the $9^{\text {th }}$ day of curing and was $100 \%$ recovered on the $28^{\text {th }}$ day of curing. This result shows that the specimen reinforced with CFRP is different from the specimens that were not reinforced with CFRP.

Upward deflection occurred in the CLT of Series-D1 in the early stage of curing for the same reason as with Series-A1 and Series-C. As the moisture content variation of the upper lamina was stabilized the upward deflection no longer increased (Series-D1) or there was a gradual increase of the downward deflection observed (Series-D2). The curing behavior of Series-D2 could be observed more accurately through analysis using AICON 3D studio. The red line in Fig. 7 visualizes the average of the deformations in the $x$ and $y$ axes of the specimen. The direction of the line indicates the deformation direction from the measurement target of the CLT, and the length of the line indicates the amount of deformation. On the $10^{\text {th }}$ day of curing, upward deflection of the lower lamina towards the center of the specimen occurred due to the swelling of the CLT's upper lamina. On the $20^{\text {th }}$ day of curing, downward deflection of the lower lamina occurred due to the self-weight, although it still had directionality towards the center of the specimen due to the drying of the CLT. Then, on the $28^{\text {th }}$ day of curing, it was observed that the self-weight contributed to the downward deflection more than the contraction of the CLT by drying.
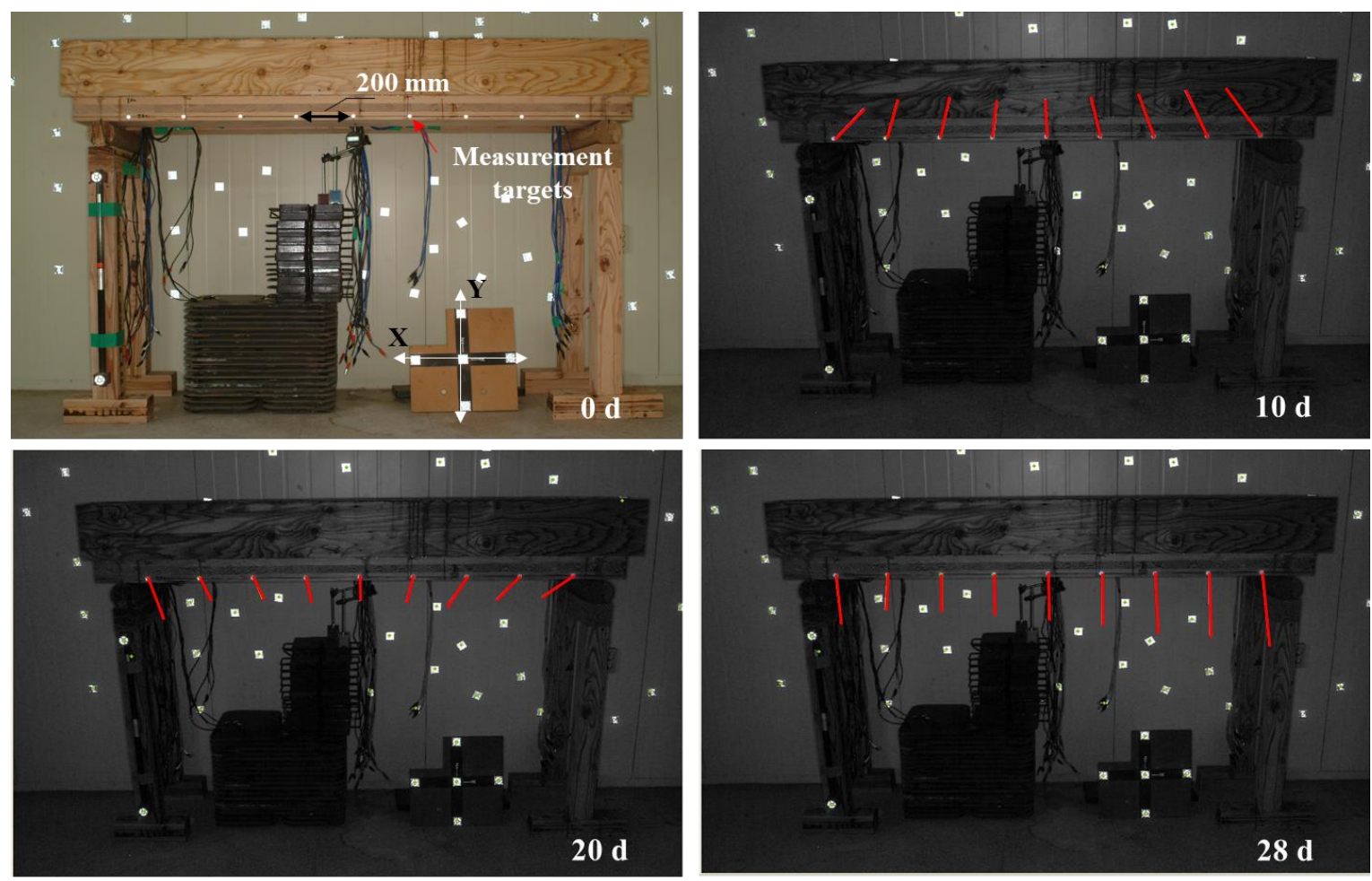

Fig. 7. Behavior of Series-D1 during the curing time based on the image analysis using AICON 3D studio 


\section{Evaluation of the Quality Performance of CCC after Curing for $\mathbf{2 8} \mathbf{d}$}

Evaluation of compressive strength for the concrete of CCC

The water loss of concrete in this stage was calculated based on the $\mathrm{MC}_{\max }$ of each CLT's upper lamina. The water losses for Series-A and Series-D were measured at 8.6\% and $2.9 \%$, respectively. The average compressive strengths of the concrete in these two series were measured $7 \%$ and $3 \%$ higher, respectively, compared to Series-B with a water loss of only $0.5 \%$. The initial W/c values for the concrete of Series-A and Series-B were 0.43 and were reduced to 0.40 and 0.42 , respectively, due to loss of moisture by CLT after curing. It was determined that this resulted in a slight increase in the strength of the concrete. However, for Series-B the W/C ratio hardly changed due to the low water loss $(0.5 \%)$, resulting in lower compressive strength compared to those of the above two specimens, but the quality was highly uniform. For Series-D, although the amount of moisture in its concrete was three times larger than that in the concrete in Series-A, the water loss of its concrete was lower than that of the concrete in Series-A because the contact area with the CLT was the same. The W/C ratio of Series-D was slightly higher than that of Series-A, and this caused the difference in compressive strength between the two specimens.

Table 1. Compressive Strength Test Results for the Concrete of the CCC Slab After Curing

\begin{tabular}{|c|c|c|c|}
\hline Specimens & $\begin{array}{c}\text { Water Loss Due to } \\
\text { CLT (\%) }\end{array}$ & $\begin{array}{c}\text { Compressive Strength } \\
(\mathbf{M P a})\end{array}$ & $\begin{array}{c}\text { Standard Deviation } \\
\text { (MPa) }\end{array}$ \\
\hline Series-A & 8.6 & $41.6(1.07)^{\star}$ & 4.2 \\
\hline Series-B & 0.5 & $38.8(1.00)$ & 1.4 \\
\hline Series-C & - & - & - \\
\hline Series-D & 2.9 & $39.8(1.03)$ & 3.5 \\
\hline
\end{tabular}

*: Compressive strength ratio to Series-B

\section{Evaluation of delamination performance to the CLT of CCC}

The suppression effect of the moisture penetration from the concrete by the epoxy bondline was verified through the delamination test results of the CLTs after curing (Fig. 8). The average delamination percentages of Series-A and Series-D, whose concrete and CLT were assumed to be shear-bonded to each other through mechanical bonding, were 14.0 and $13.1 \%$, respectively. A relatively high delamination percentage was observed in bondline A, adjacent to the upper layer of CLT, which received the greatest effect of moisture from the concrete during the curing time. The average delamination percentage of Series-B, whose concrete and CLT were shear-bonded to each other through an epoxy adhesive, was very low $(3.7 \%)$.

The above results confirm that wet construction method for manufacturing CCC influences the moisture content of CLT and especially degrades the delamination performance of CLT. Furthermore, for the method of using epoxy adhesive for the shear bonding between concrete and CLT, the epoxy bondline plays the role of suppressing the degradation of the CLT's delamination performance by the concrete moisture during the curing time. In general, the bonding strength of CLT is evaluated lower than that of glulam (Song and Hong 2016). Thus, the delamination performance of CLT is more closely related to the quality of products. However, the findings of this study contradict the argument that the wet construction method using mechanical shear connectors is inadequate. To confirm this argument, additional research on long-term load is required. 


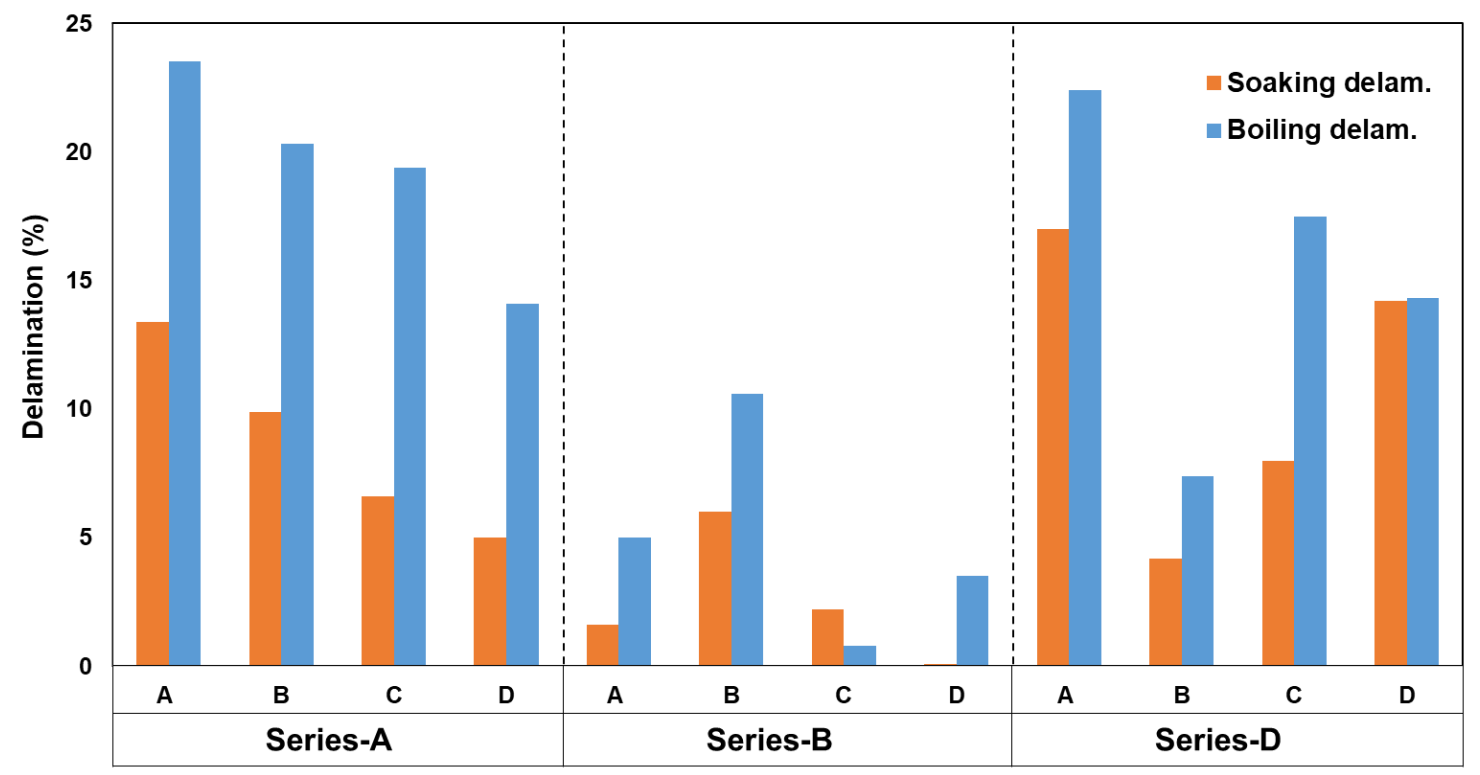

Fig. 8. Delamination test results for the CLT of the CCC slab after curing

\section{CONCLUSIONS}

This study aimed to examine the effects of the concrete moisture on the quality of slabs comprised of cross-laminated timber (CLT) and concrete when fabricating CCC slabs using the wet construction method. All the research outcomes are referred to ordinary ambient conditions and design loads.

1. When CCC slabs are manufactured using the wet construction method, the existing mechanical shear connections between the CLT and the concrete leaves the CLT unguarded against the moisture penetrating it from the concrete. Furthermore, it was found that moisture transfer from the concrete to the CLT caused uniformity deterioration through water loss from the concrete itself, resulting in the degradation of and delamination between the laminae for the CLT that had absorbed moisture.

2. Suppression of the moisture penetration from the concrete to the CLT during the curing time was achieved through the shear bonding method using an epoxy adhesive between the CLT and the concrete. It was found that this effect could prevent the uniformity degradation of the concrete and degradation of the delamination performance of the CLT.

3. The carbon fiber reinforced plastic (CFRP) attached to the tensile zone of the CCC slab played the role of quickly reversing the deformation of the CLT by the concrete moisture.

4. For CCC slabs with the same CLT size, it was found that there was no correlation between the amount of concrete poured and the delamination performance of the CLT. 


\section{ACKNOWLEDGEMENTS}

This research was supported by a grant (19RERP-B082884-06) from the Residential Environment Research Program funded by the Ministry of Land, Infrastructure and Transport of Korean government.

\section{REFERENCES CITED}

Adesanya, D. A., and Raheem, A. A. (2009). "A study of the workability and compressive strength characteristics of corn cob ash blended cement concrete," Construction and Building Materials 23(1), 311-317. DOI: 10.1016/j.conbuildmat.2007.12.004

Alawode, O., and Idowu, O. I. (2011). "Effects of water-cement ratios on the compressive strength and workability of concrete and lateritic concrete mixes," The Pacific Journal of Science and Technology 12(2), 99-105.

ASTM C39 (2012). "Standard test method for compressive strength of cylindrical concrete specimens," ASTM, West Conshohocken, PA, USA.

Bajzecerová, V. (2017). "Bending stiffness of CLT-concrete composite members comparison of simplified calculation methods," Procedia Engineering 190, 15-20. DOI: 10.1016/j.proeng.2017.05.301

Burnham, T., and Koubaa, A. (2001). "A new approach to estimate the in-situ thermal coefficient and drying shrinkage for jointed concrete pavement," in: Proceedings of the 7th International Conference on Concrete Pavements, Orlando, FL, USA, pp. 313-332.

Darby, H. J., Elmualim, A. A., and Kelly, F. (2013). "A case study to investigate the life cycle carbon emissions and carbon storage capacity of a cross laminated timber, multi-storey residential building," in: Proceedings of the Sustainable Building Conference, Munich, Germany, pp. 10-12.

Dodoo, A., Gustavsson, L., and Sathre, R. (2014). "Lifecycle carbon implications of conventional and low-energy multi-storey timber building systems," Energy and Buildings 82, 194-210. DOI: 10.1016/j.enbuild.2014.06.034

Frangi, A., Knobloch, M., and Fontana, M. (2010). "Fire design of timber-concrete composite slabs with screwed connections," Journal of Structural Engineering 136(2), 219-228. DOI: 10.1061/(ASCE)ST.1943-541X.0000101

Fu, Q., Yan, L., Ning, T., Wang, B., and Kasal, B. (2020). "Interfacial bond behavior between wood chip concrete and engineered timber glued by various adhesives," Construction and Building Materials 238, Article ID 117743. DOI:

10.1016/j.conbuildmat.2019.117743

Gong, Y., Wu, G., and Ren, H. (2016). "Block shear strength and delamination of crosslaminated timber fabricated with Japanese larch,” BioResources 11(4), 10240-10250. DOI: $10.15376 /$ biores.11.4.10240-10250

Harte, A. M. (2017). "Mass timber - The emergence of a modern construction material," Journal of Structural Integrity and Maintenance 2(3), 121-132. DOI: $10.1080 / 24705314.2017 .1354156$

Heath, A. C., and Roesler, J. R. (2000). "Top-down cracking of rigid pavements constructed with fast-setting hydraulic cement concrete," Journal of the Transportation Research Board 1712(1), 3-12. DOI: 10.3141/1712-01 
Jeong, J. H., Lim, J. S., Sun, R. J., and Zollinger, D. G. (2012). "Modelling of differential shrinkage of pavement slabs," Proceedings of the Institution of Civil EngineersTransport 165(1), 3-14. DOI: 10.1680/tran.10.00020

Jiang, Y., and Crocetti, R. (2019). "CLT-concrete composite floors with notched shear connectors," Construction and Building Materials 195, 127-139. DOI: 10.1016/j.conbuildmat.2018.11.066

Kanócz, J., and Bajzecerová, V. (2015). "Timber-concrete composite elements with various composite connections. Part 3: Adhesive connection," Wood Research 60(6), 939-952.

Knorz, M., Torno, S., and Van de Kuilen, J. W. (2017). "Bonding quality of industrially produced cross-laminated timber (CLT) as determined in delamination tests," Construction and Building Materials 133, 219-225. DOI: 10.1016/j.conbuildmat.2016.12.057

KS F 2160 (2013). "Delamination of resistance to soaking delamination for adhesivebonded wood products," Korean Standards Association, Seoul, South Korea.

KS F 2199 (2016). "Determination of moisture content of wood," Korean Standards Association, Seoul, South Korea.

KS F 3021 (2016). "Structural glued laminated timber," Korean Standards Association, Seoul, South Korea.

Lehmann, S. (2013). "Low carbon construction systems using prefabricated engineered solid wood panels for urban infill to significantly reduce greenhouse gas emissions," Sustainable Cities and Society 6, 57-67. DOI: 10.1016/j.scs.2012.08.004

Liao, Y., Tu, D., Zhou, J., Zhou, H., Yun, H., Gu, J., and Hu, C. (2017). "Feasibility of manufacturing cross-laminated timber using fast-grown small diameter eucalyptus lumbers," Construction and Building Materials 132, 508-515. DOI:

10.1016/j.conbuildmat.2016.12.027

Lim, H., Tripathi, S., and Tang, J. D. (2020). "Bonding performance of adhesive systems for cross-laminated timber treated with micronized copper azole type C (MCA-C)," Construction and Building Materials 232, Article ID 117208. DOI:

10.1016/j.conbuildmat.2019.117208

Lim, S., Jeong, J. H., and Zollinger, D. G. (2009). "Moisture profiles and shrinkage in early-age concrete pavements," International Journal of Pavement Engineering 10(1), 29-38. DOI: 10.1080/10298430802279801

Liu, Y., Guo, H., Sun, C., and Chang, W. S. (2016). "Assessing cross laminated timber (CLT) as an alternative material for mid-rise residential buildings in cold regions in China - A life-cycle assessment approach," Sustainability 8(10), Article number 1047. DOI: $10.3390 /$ su8101047

Mahdavifar, V., Barbosa, A., Sinha, A., Muszynski, L., and Gupta, R. (2016). "Hysteretic behaviour of metal connectors for hybrid (high-and low-grade mixed species) cross laminated timber," in: $14^{\text {th }}$ World Conference on Timber Engineering, Vienna, Austria.

Mai, K. Q., Park, A., Nguyen, K. T., and Lee, K. (2018). "Full-scale static and dynamic experiments of hybrid CLT-concrete composite floor," Construction and Building Materials 170, 55-65. DOI: 10.1016/j.conbuildmat.2018.03.042

Meddah, M. S., Zitouni, S., and Belâabes, S. (2010). "Effect of content and particle size distribution of coarse aggregate on the compressive strength of concrete," Construction and Building Materials 24(4), 505-512. DOI:

10.1016/j.conbuildmat.2009.10.009 
Mudie, J., Sebastian, W. M., Norman, J., and Bond, I. P. (2019). "Experimental study of moment sharing in multi-joist timber-concrete composite floors from zero load up to failure," Construction and Building Materials 225, 956-971. DOI: 10.1016/j.conbuildmat.2019.07.137

Ogrin, A., and Hozjan, T. (2020). "Fire resistance of timber-concrete composite slabs," Materials and Structures 53(4), 1-15. DOI: 10.1617/s11527-020-01540-6

Park, A. R., and Lee, K. (2019). "Experimental and analytical study of shear connectors for the CLT-concrete composite floor system," Journal of the Korean Association for Spatial Structures 19(1), 65-73. DOI: 10.9712/KASS.2019.19.1.65

Shen, D., Liu, C., Li, C., Zhao, X., and Jiang, G. (2019). "Influence of barchip fiber length on early-age behavior and cracking resistance of concrete internally cured with super absorbent polymers," Construction and Building Materials 214, 219-231. DOI: 10.1016/j.conbuildmat.2019.03.209

Song, Y. J., and Hong, S. I. (2016). "Evaluation of bonding strength of larch crosslaminated timber," Journal of The Korean Wood Science and Technology 44(4), 607615. DOI: 10.5658/WOOD.2016.44.4.607

Song, Y. J., Lee, I. H., and Hong, S. I. (2019). "Evaluation of horizontal shear performance of larch CLT walls according to the edge connection shape," Wood Research 64(2), 213-222.

Song, Y. J., Lee, I. H., Song, D. B., and Hong, S. I. (2019). "Evaluation of delamination and bending performance of composite CLT reinforced with CFRP," Wood and Fiber Science 51(4), 354-363. DOI: 10.22382/wfs-2019-034

Teguedy, M. C., Joly-Lapalice, C., Sorelli, L., and Conciatori, D. (2019). “Optical fiber sensors implementation for monitoring the early-age behavior of full-scale timberconcrete composite slabs," Construction and Building Materials 226, 564-578. DOI: 10.1016/j.conbuildmat.2019.07.294

Thilén, J. (2017). Testing of CLT-Concrete Composite Decks (Report number: TVBK5259), Lunds University, Lund, Sweden.

Timmers, M., and Jacobs, A. T. (2018). "Concrete apartment tower in Los Angeles reimagined in mass timber," Engineering Structures 167, 716-724. DOI: 10.1016/j.engstruct.2017.11.047

Tumidajski, P. J., and Gong, B. (2006). "Effect of coarse aggregate size on strength and workability of concrete," Canadian Journal of Civil Engineering 33(2), 206-213. DOI: $10.1139 / 105-090$

United Nations (2018). World Urbanization Prospects 2018 (Working paper No. ESA/P/WP.252), United Nations Department for Economic and Social Affiars, New York, NY, USA.

Article submitted: August 6, 2020; Peer-review completed: September 20, 2020; Revised version received: November 12, 2020; Accepted: November 13, 2020; Published:

November 18, 2020.

DOI: 10.15376/biores.16.1.372-386 